\title{
BBA Lab a Virtual Laboratory for Distant Learning
}

\author{
Samir Akrouf, Djamel Boubetra, Jean-Jacques Charlot, Larbi Selmani, Abdelhak Boubetra, and Adel \\ Merabet, Member, IACSIT
}

\begin{abstract}
Nowadays distant learning is gaining more and more popularity due to the technological development and the flexibility it offers for the students. All around the world we see universities conceiving their distant learning platforms in order to offer to their students this service and help them study at their own pace. In this paper we describe BBA lab a draft of the distant lab of Bordj Bou Arreridj University. It is dedicated mainly to students in the field of electrical engineering and computer science. Bordj Bou Arreridj University is involved in a project which is financed by the Eurepean Community and aims to link three distant Elabs, the Algerian Elab, developed by Constantine 1 and Bordj Bou Arreridj Universities, the Moroccan and the Tunisian Elabs.
\end{abstract}

Index Terms-Distant Elabs, internet, work packages, simulation.

\section{INTRODUCTION}

Great developments in education have been achieved in the last two decades; this is due to the large use of internet and personal computers. This new way of life imposes for educational institutions to innovate and use these tools to offer to their students' facilities to enroll to specific courses and study remotely [1].

BBA Elab as stated earlier is a part of a TEMPUS project financed by the European Community. ESience is its acronym it stands for "rESeau maghrébIn de laboratoirEs à distaNCE". The project is coordinated by Bordeaux 1 University from France with the participation of many other European partners. These Elabs will offer, online, practical and theoretical teachings which will be used by their students as part of their degree programs. The project is divided in several work packages and in each one several tasks have to be accomplished. The first work package involves the definition and the conception of the teaching units. We have to develop two out of fifteen initially programmed for this project. The first one is the "Study and Utilization of Simulators Associated to Remote Characterization of Circuits and Systems" [2], the second one is "Biometric Identification" [3].

\section{BBA LAB ARCHITECTURE}

\section{A. The Architecture}

The architecture of the Elab is composed by two different servers dedicated to different tasks:

- The BBA Lab Server is the visible part of the Elab for the users via internet.

- The Simulation Server gives the students the possibility to do their simulation on electronic components.

This severs were installed on Linux platform and use LAMP structure (Linux-Apache-MySql-PHP).

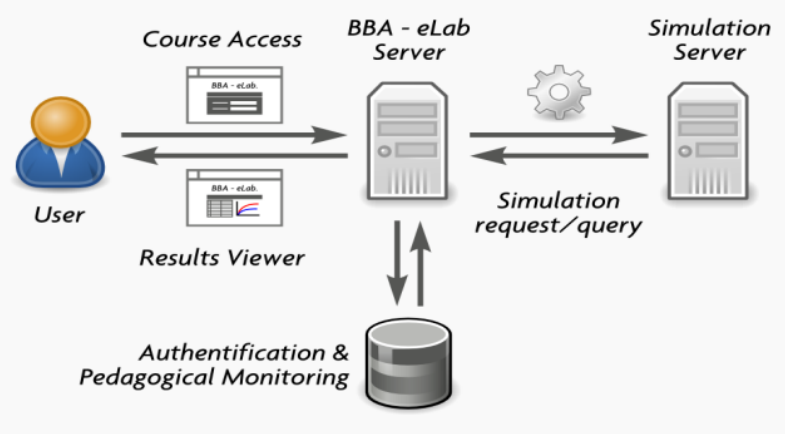

Fig. 1. BBA Elab architecture.

\section{B. Multimedia Lab}

The first task was the Installation of a networked lab then the configuration of 20 personal computers which will be used by our students when they are on campus. The following is a photo of the lab (see Fig. 2):

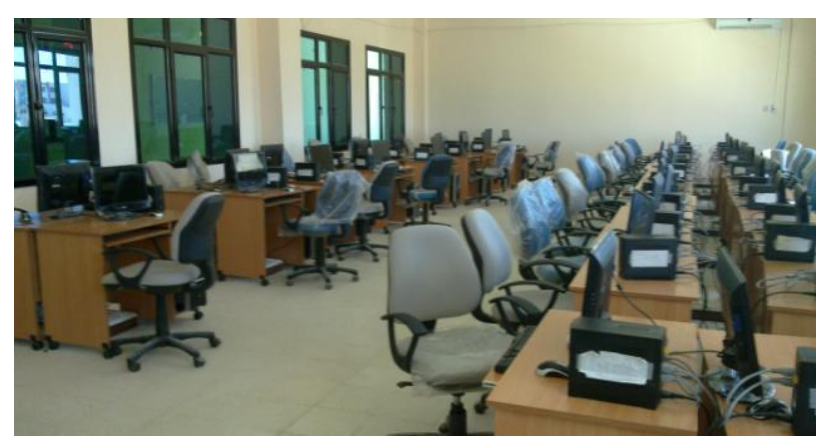

Fig. 2. BBA multimedia lab.

\section{The BBA Lab Server}

We Used the Moodle (Modular Object-Oriented Dynamic Learning Environment) [4], [5] platform which is from our point of view best suited for academic institutions. The following is the first login page for users (see Fig. 3).

The user either has an account, so he can access directly or he can contact us in order to enroll and give him an account to access the platform. After his authentification he will see the 
following and begin using the platform (see Fig. 4):

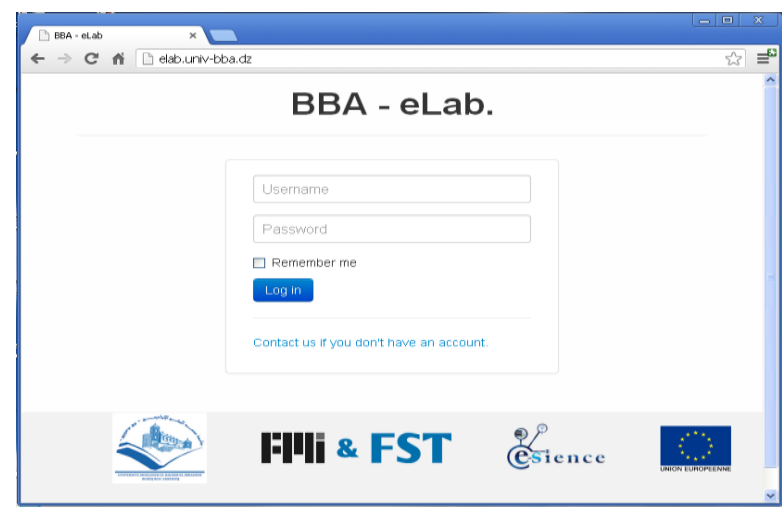

Fig. 3. Login page.

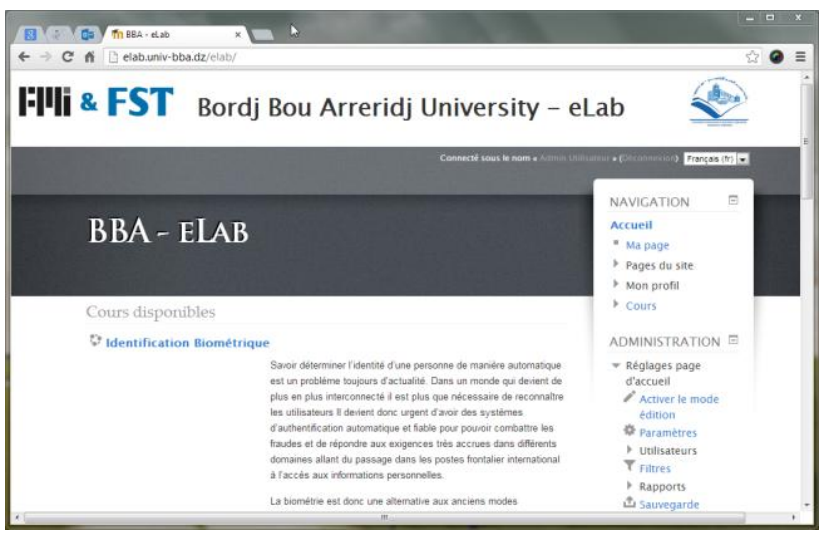

Fig. 4. Proposed courses.

\section{The Simulation Server}

This server is configured under Linux Red Hat Server Distribution. We acquired a license for AMS (Analog and Mixed Signals) [6] from SILVACO, which includes SMARTSPICE, an electrical circuit simulator, for device modeling, characterization and optimization of model parameters. The following page will be used by students to access the server guided by an interface which will introduce his data to the server who will process them and then give him the simulation results (see Fig. 5).

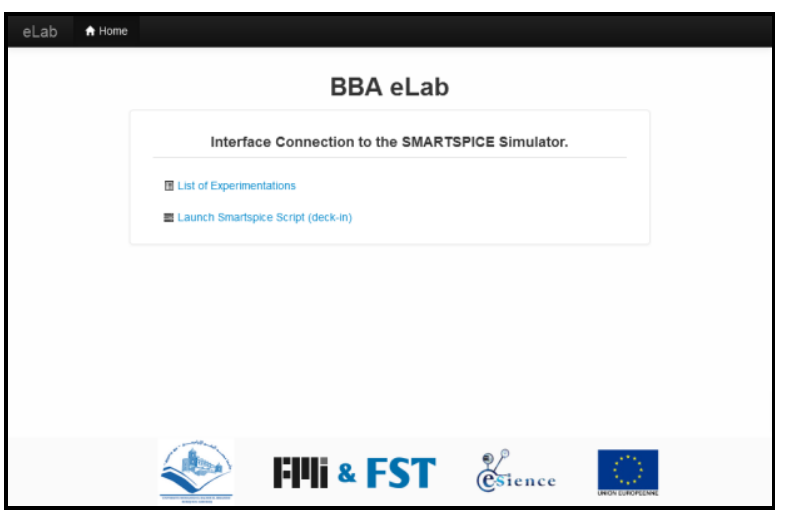

Fig. 5. Interface giving access to the simulation server.

The process of execution of the simulation is illustrated by the following diagram (see Fig. 6):

The following is an example of the use of the server in order to get the characteristics of electronic circuits.

A set of measurements have been performed via Internet at the eLab remote characterisation platform of Bordeaux University to get electrical characteristics IDS (VDS). VDS sweeping from 0 to $3 \mathrm{~V}, \mathrm{VGS}=2.0$ and $3.0 \mathrm{~V}, \mathrm{VBS}=0.0 \mathrm{~V}$ SMARTSPICE deck-in will be introduced using the interface described in Fig. 5. The following interface is used to introduce the data (see Fig. 7):

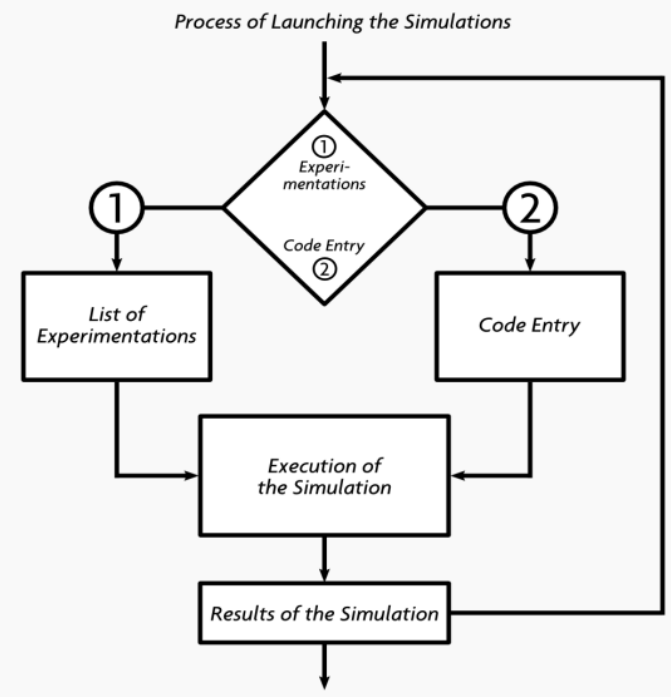

Fig. 6. Diagram of the process launching the simulations.

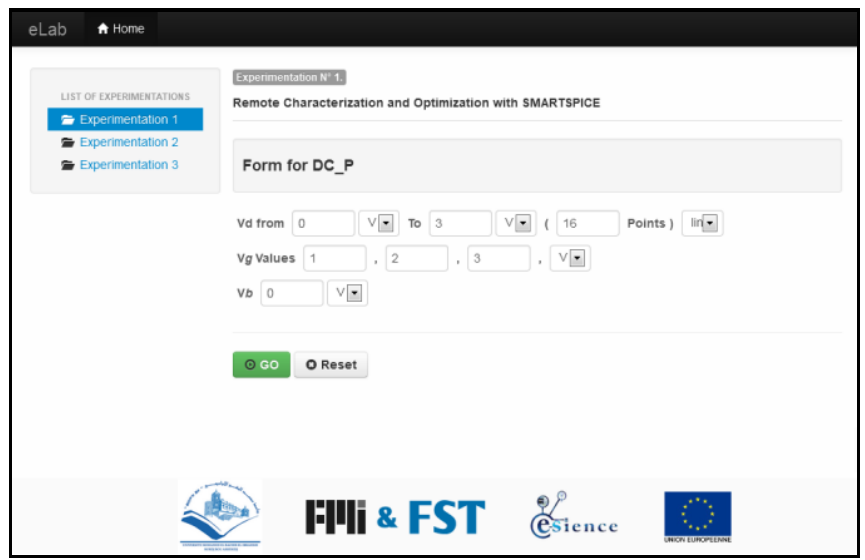

Fig. 7. Interface of the introduction of the data.

The simulation results give the comparison of simulated and experimental characteristics after optimization (see Fig. 8). The curves are superposed (these curves were plot by Pylab, a tool from matplotlib [7]).

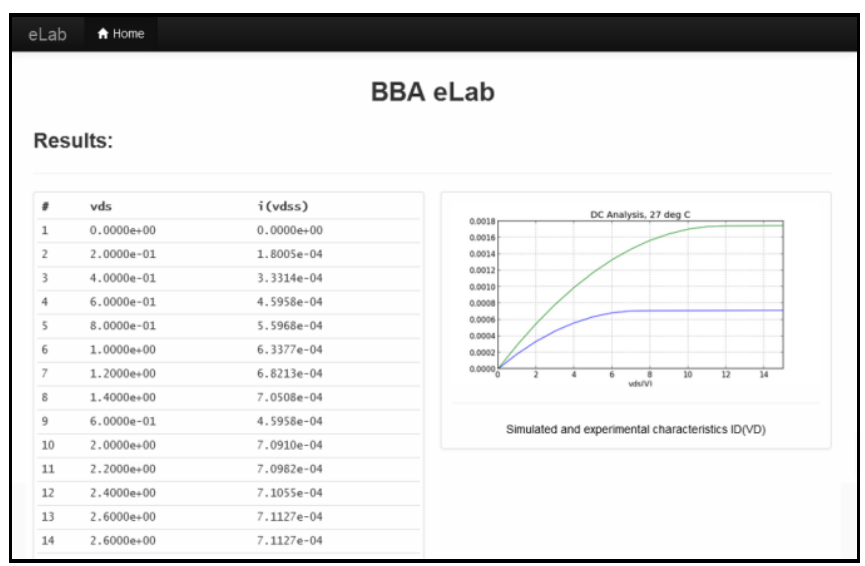

Fig. 8. Simulated and experimental characteristics ID(VD).

In the same time SMARTSPICE gives optimization results about parameters in an output file which can be visualized easily. 


\section{CONCLUSION}

We presented in this paper the general architecture of BBA Lab which is a virtual laboratory and will be used by our students. The lab is under development and will be enriched by many other teaching units and theoretical notions. Its content will have a great impact on the process of studying of our students and will be certainly of great help to them since they can study at their own pace and from everywhere. The lab will be linked to the other labs, Constantine 1, Morocco and Tunisia labs, as soon as they will be accessible and the students from the three countries will have access to all their contents.

\section{ACKNOWLEDGMENT}

The authors which to thank ALCOMSYS team and Professor Ferhat Hmida for their collaboration in the project.

\section{REFERENCES}

[1] T. Zimmer, M. Billaud, and D. Geoffroy, "A remote laboratory for electrical engineering education," IMCL2006, April 19-21, 2006 Amman, Jordan.

[2] J. J. Charlot, L. Selmani, S. Akrouf, D. Boubetra, and A. Boubetra, "Study and Utilization of simulators Associated to Remote characterization of Circuits and Systems," in Proc. International Conference on Engineering and Research 2013, 1 July-5 July 2013, Marrakesh.

[3] S. Akrouf, L. Selmani, D. Boubetra, and M. Mostefai, "A Biometric Identification Course for Esience Virtual Lab," presented at 2013 4th International Conference on Software and Computing Technology (ICSCT 2013), October 24-25, 2013, Konya Turkey.

Faculty opinions of Moodle: spring survey 05. Earlham College. [Online]. Available: http://www.earlham.edu/\%7Emarkp/cms/evaluations/faculty_05/sprin g_survey.php.

[4] Moodle Services. (2004). Welcome to the Moodle Service Network! [Online]. Available: http://moodle.com/

[5] Smart Spice user's guide. [Online]. Available: www.silvaco.com

[6] Matplotlib. [Online]. Available: http://matplotlib.org/

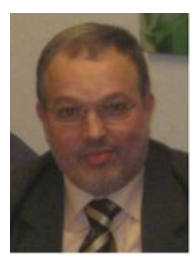

Samir Akrouf was born in Bordj Bou Arreridj, Algeria in 1960. He received his engineer degree from Constantine University, Algeria in 1984. He received his master's degree from University of Minnesota, USA in 1988. He received his $\mathrm{PhD}$ degree from University of Setif Algeria. Currently; he is an associate professor at the Computer department of Bordj Bou Arréridj
University, Algeria. He is an IACSIT member and is a member of LMSE laboratory (a research laboratory in Bordj Bou Arreridj University). He is also the dean of Mathematics and Computer Science Facultyy of Bordj Bou Arreridj University. His main research interests are focused on Biometric Identification, Computer Vision, Computer Networks and Social Network Analysis.

Boubetra Djamel was born in Bordj Bou Arreridj Algeria in 1960. He received his engineer degree in Mechanics in 1984 from Setif University. He received his PhD in 1992 from Humboldt University Berlin Germany.

Currently; he is an associate professor at the Electrical Engineering Department of Bordj Bou Arréridj University, Algeria. He is also the vice director of foreign relations. His main research interests are focused on Biometric Identification, Distant Learning, Simulation and computer aided design.

Jean-Jacques Charlot was born in Vitry le François, France the $11^{\text {th }}$ of April 1943. He got his Doctorate Third degree in 1967 in Electronics from University Paris XI, Orsay. He got his Doctorate degree in 1973 in Physics from University Paris XI, Orsay.

Currently; he is a visiting professor at the Electrical Engineering Department of Bordj Bou Arréridj University, Algeria. He is also an International Consultant.

Selmani Larbi was born in El Eulma Algeria in 1955. He received his bachelor degree in physics in 1978 from Algiers University. He received his PhD in 1985 from INSA de Lyon University France.

Currently; he is a professor at the Electrical Engineering Department of Bordj Bou Arréridj University, Algeria. He is also the Dean of Technical Science Faculty of Bordj Bou Arréridj University, Algeria. His main research interests are focused on Biometric Identification, Distant Learning, Simulation and Computer Aided Design.

Boubetra Abdelhak was born in Bordj Bou Arreridj, Algeria in 1959. He received his Engineer degree from Constantine University, Algeria in 1985. He received his Master's degree from Great Britain in 1990. He received his $\mathrm{PhD}$ degree from University of Setif Algeria.He got his HDR Habilitation Universitaire in 2011. Currently; he is a professor at the Computer Science department of Bordj Bou Arreridj University, Algeria. His main research interests are focused on Computer Business Intelligence, Simulation and E-commerce.

Merabet Adel was born in 1988 in Bordj Bou Arreridj Algeria. He got his bachelor degree in Computer Science in 2011 from Bordj Bou Arreridj University. Currently he is preparing his Master Degree he will graduate in 2014 . 